\title{
A Special Issue on Geomathematics for Real-Time Mining
}

\author{
Jörg Benndorf ${ }^{1}$. Mike Buxton ${ }^{2}$
}

Published online: 23 September 2019

(C) International Association for Mathematical Geosciences 2019

The flow of information, and consequently the decisions made along the chain of mining from exploration to beneficiation, typically occur in a discontinuous fashion over a long time span. In addition, due to the uncertain nature of the knowledge regarding mineral deposits and the inherent spatial distribution of material characteristics, actual production performance often deviates from expectations. Reconciliation exercises to adjust mineral resource/reserve models and planning assumptions are performed with time lags of weeks, months or even years.

"Real-Time Mining" was a multi-partner, multinational R\&D project funded by the European Commission (European Union Horizon 2020 research and innovation programme under grant agreement no. 641989). Launched in 2014, the project was successfully completed in 2019 with a demonstration day in an underground mining setting (Benndorf et al. 2015). The key concept of real-time mining is to promote the paradigm shift from discontinuous intermittent process monitoring to a continuous process and quality management system in resource extraction (Fig. 1). The framework includes a real-time feedback control loop that rapidly links online data acquired during the extraction at the mining face and during the material handling and processing with a sequential resource model that can be updated. This will allow for the near real-time

\footnotetext{
$凶$ Jörg Benndorf

Joerg.benndorf@mabb.tu-freiberg.de

Mike Buxton

M.W.N.Buxton@tudelft.nl

1 TU Bergakademie Freiberg, Freiberg, Germany

2 TU Delft, Delft, The Netherlands
} 

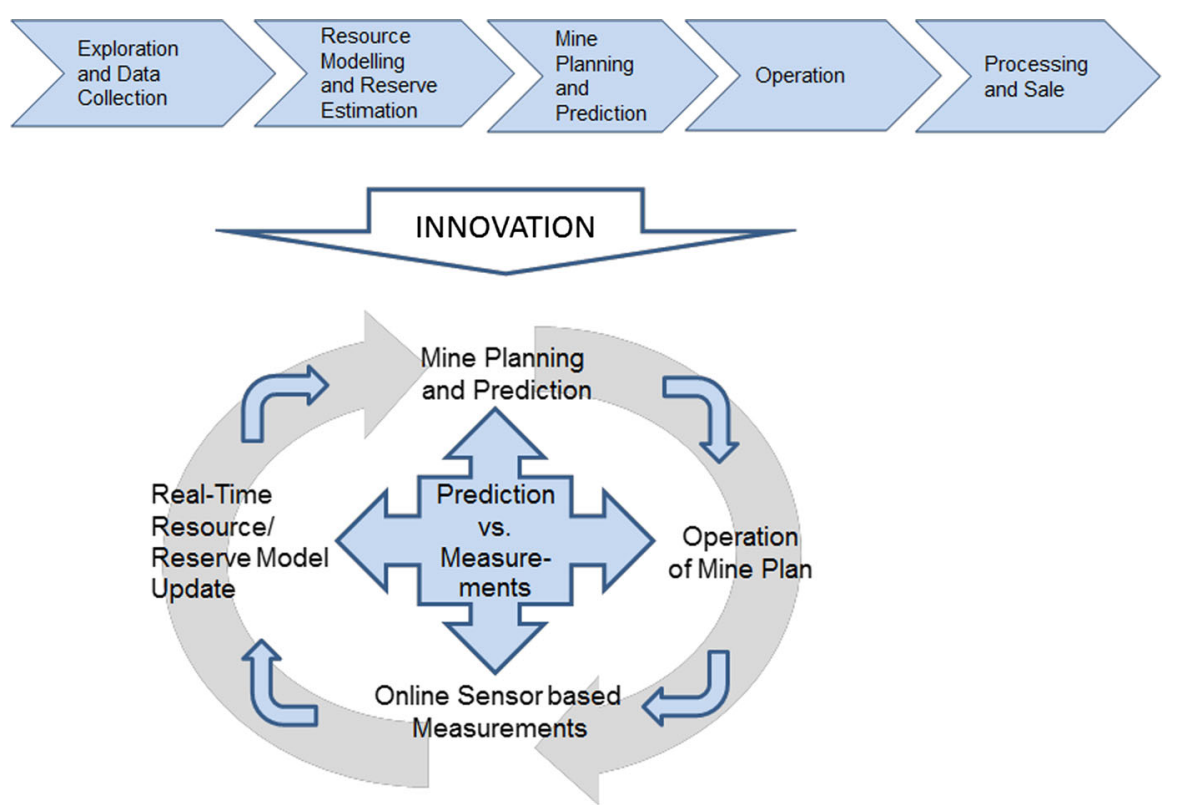

Fig. 1 Moving from a discontinuous process to a real-time continuous closed-loop process

optimization of decisions related to long-term mine planning, short-term sequencing and production control.

The development of an integrated framework such as that described above and in the context of mineral resource management involves significant scientific challenges, as it integrates multiple distinct scientific disciplines into one coherent process-monitoring and optimization framework. The main building blocks within the Real-Time Mining project were (i) underground equipment positioning, (ii) sensor-based material characterization, (iii) sensor-based machine control monitoring, (iv) methods of spatial grade prediction using geostatistical approaches and rapid updating, and (v) optimization of short-term planning. The key enabler that turns data into mining intelligence is the management of a large and heterogeneous database and intuitive visualization (Buttgereit et al. 2016). In general, real-time mining can be seen as a main component for a digital mine or Mining 4.0.

This special issue is dedicated to developments from the Real-Time Mining R\&D project, and documents selected results and related applications. The basis of RealTime Mining R\&D outputs is the ability to characterize the ore and material stream within the mining process online. In the first two manuscripts of this special issue, Dalm, Buxton and van Ruitenbeek, followed by Desta and Buxton, present solutions for ore and ore-waste discrimination based on near-infrared to short-wavelength infrared and mid-wave infrared spectral reflectance data obtained from images of samples and the mining face. To unlock the potential of these data, it is necessary to integrate them rapidly into spatial models. Along this direction, Neves, Pereira, Pacheco and Soares present a solution for updating reserves with uncertain data based on direct sequential simulation. This approach allows one to deal with soft sensor 
information from handheld X-ray fluorescence (XRF) sensors and is applied at the Neves Corvo ore body in Portugal. Next, an alternative approach for resource model updating based on the ensemble Kalman filter developed by Wambeke and Benndorf (2017) is further investigated by Yüksel, Minnecker, Shishvan, Benndorf and Buxton. In the latter manuscript, the model updating is combined with a short-term optimizer to not only define the extraction sequence in a lignite deposit, but also quantify the value of additional information. This particular application demonstrates that an operationally implemented real-time mining concept has a payback period of less than a year.

We hope that you will enjoy this special issue, which aims to both provide an overview of core results from the Real-Time Mining R\&D project and stimulate further interest in the broader topic.

\section{The Guest Editors}

\section{References}

Benndorf J, Buxton MWN, Nienhaus K, Rattmann L, Korre A, Soares A, de Jong A, Jeannee N, Graham P, Buttgereit D, Gehlen S, Eijkelkamp F, Mischo H, Sandtke M, Wilsnack T (2015) Real-time mining-moving towards continuous process management in mineral resource extraction. In: Seydam $\mathrm{S}$ (ed) Proceedings of the 3rd international future mining conference, Sydney. The Australian Institute of Mining and Metallurgy, Melbourne, Victoria, Australia

Buttgereit D, Bitzen, S, Benndorf J, Buxton M (2016) Real-time mining: grade monitoring und control cockpit. In: Nienhaus K, Burgwinkel P (eds) Proceedings of the 11th Aachen conference on maintenance, machine diagnostics and condition monitoring, AKIDA 2016, Aachen, Germany, 15-16 Nov 2016, pp 49-60

Wambeke T, Benndorf J (2017) A simulation-based geostatistical approach to real-time reconciliation of the grade control model. Math Geosci 49(1):1-37 